\title{
Консолидация практик экологического менеджмента и управления человеческими ресурсами как ключевой фактор развития корпоративной экологической ответственности компании
}

\section{Галина Арзамасова}

Пермский национальный исследовательский политехнический университет, г. Пермь, Россия

\author{
Информация о статье \\ Поступила в редакичию: \\ 13.07.2020 \\ Принята \\ к опубликованию: \\ 10.10.2020 \\ УДК 504.03 \\ JEL Q52, M59
}

\section{Ключевые слова:}

экологическая ответственность бизнеса, система экологического менеджмента, персонал, экологическое управление человеческими ресурсами, экологическая результативность

\footnotetext{
Keywords:

corporate environmental responsibility, environmental management system, green human resource management, employees
}

\begin{abstract}
Аннотация
Современная практика российских и зарубежных компаний в области рацчионального природопользования показывает, что ее успех в значительной степени зависит как от состояния системы экологического менеджмента, так и от степени интеграции деятельности по управлению персоналом в процессы реализации экологических стратегий. В статье представлен анализ и дана характеристика практик управления человеческими ресурсами, применительно к моделям систем экологического менеджмента (реактивной, превентивной и проактивной), которые совместно вносят вклад в развитие корпоративной экологической ответственности компании.
\end{abstract}

Consolidation of Environmental Management and Human Resources Management Practices as a Key Factor in the Development of the Company's Corporate Environmental Responsibility

Galina Arzamasova

\section{Abstract}

In Russian and foreign companies, the environmental performance and success of environmental practices depend on the nature of the interaction between the environmental management system and human resources management activities. The objective of the paper: to identify HR practices that meet the environmental management goals and promote the development of the company's corporate environmental responsibility. The research method: analysis and systematization of scientific papers in the field of corporate environmental responsibility, environmental management and Green Human Resource Management. The results: HR practices model was 
developed that corresponds to three models of the environmental management system (EMS): reactive, preventive and proactive. Human resources management (HRM) activities are separated from the environmental functions and tasks in the EMS reactive model; the preventive EMS model is characterized by the interaction of human resources and environmental services in the common business processes for staff selection, training and evaluation as well as the performance management; the proactive EMS model includes the greening of HR policies and all processes aimed at involving employees in environmental activities. The paper justifies the necessity to expand HR practice in preventive and proactive EMS models. This will consolidate the opportunities for HRM and EMS to develop corporate environmental responsibility of companies. The results can be the basis for further theoretical and empirical research as well as for the diagnosing and assessing the degree of the HR systems compliance with the company's environmental goals.

\section{Введение}

В конце XX в., параллельно с нарастанием экологических проблем и переходом к модели устойчивого развития, происходят изменения требований к экологической безопасности производств, формируя представление о корпоративной экологической ответственности (далее - КЭО) как о важной составляющей бизнес-моделей современных предприятий, которая является не только необходимым условием успешной предпринимательской деятельности, но и фактором их устойчивого развития и конкурентоспособности $[1,2]$. Еще недавно компании делали ставку на создание надежных систем управления природоохранной деятельностью и внедрение стандартов экологического менеджмента, обеспечивающих экологическую безопасность производства и его эколого-правовую легитимность, добиваясь высокой экологической результативности. Однако практика внедрения концепции КЭО на предприятиях показала необходимость формирования экологических стратегий и долгосрочных механизмов их реализации, основанных на консолидации систем экологического менеджмента (далее - СЭМ) и управления человеческими ресурсами (далее УЧР), так как отсутствие взаимосвязи между экологическим менеджментом и УЧР демонстрирует наивную веру в то, что современные управленческие подходы и использование природоохранных технологий обеспечивают решения проблем в области охраны окружающей среды. Это является результатом технологического оптимизма, который может помочь организациям в их экономических показателях, но не создает пути к устойчивому развитию, поскольку он не учитывает этические и поведенческие изменения [3].

Более 40 лет ученые исследуют влияние практик УчР на достижение целей экологически устойчивого развития, эффективность СЭМ и достижение экологических результатов отдельных процессов и организаций в целом $[4,5]$. Сегодня уже нет сомнения в том, что такая взаимосвязь существует и корпоративные экологические стратегии будут успешными в том случае, если будут включать практики в области УЧР, которые можно рассматривать как ключевую детерминанту экологической составляющей устойчивого развития [4], поскольку именно они позволяют мобилизовать сотрудников, содействовать скоординированным действиям и экологическим инициативам, способствовать этичному экологическому поведению людей и повышению уровня экологической ответственности организаций [3].

В настоящее время методологической основой для теоретических и прикладных исследований в УЧР организации, ориентированной на экологиче- 
скую устойчивость, является активно развивающаяся концепция экологического УЧР (Green Human Resource Management - GHRM), подразумевающего использование методов УЧР для усиления экологически устойчивых практик, обеспечивающих стратегическую экологическую ориентацию организации с фокусом на организационные процессы и практики, которые поддерживают деятельность по защите окружающей среды, повышают приверженность сотрудников и их обязательства по экологической устойчивости $[6,7]$. Тем не менее, до сих пор вклад УЧР в развитие СЭМ и КЭО с точки зрения теории рассматривается поверхностно и эмпирически мало изучен [8]. В частности, значимой научной проблемой остается вопрос о формировании практик УчР, совместимых с задачами экологического менеджмента, и обеспечивающих переход компании на более высокий уровень КЭО.

\section{Цель, материалы и методы исследования}

Цель исследования заключается в разработке моделей УЧР, согласующихся с задачами экологического менеджмента и содействующих развитию корпоративной экологической ответственности компании. В русле этой цели исследование включало две задачи: во-первых, выявление моделей СЭМ, связанных с разными уровнями развития КЭО, и, во-вторых, идентификация практик УЧР, соответствующих конкретным моделям, СЭМ.

Описание моделей СЭМ осуществлялось на основе анализа и систематизации российских и зарубежных научных работ в областях экологического менеджмента и экологической ответственности бизнеса. Существенные атрибуты практик УЧР были установлены путем синтеза теоретических и эмпирических результатов в области экологического УЧР. База научных публикаций охватывает период с 1995 по 2020 год, что позволило аргументировано обосновать авторскую позицию по обозначенным выше вопросам.

\section{Результаты исследования и их обсуждение}

Концепция КЭО подразумевает дополнительные усилия организаций, учитывающих экологические аспекты и взаимодействие с заинтересованными сторонами, которые могут снизить экологические последствия внедренных бизнес-операций, созданных продуктов и используемых средств посредством комплекса инициатив, направленных на уменьшение «экологического следа» организации и не противоречащих принципам эффективного корпоративного управления $[9,10,11]$. Уровень КЭО отражает степень, в которой компания следует принципам минимизации отрицательного влияния на окружающую среду и демонстрирует заинтересованным сторонам экологически ответственное поведение в рамках всей продуктовой цепочки и жизненного цикла продукции.

Анализ научных работ, рассматривающих КЭО как элемент корпоративной социальной ответственности, а также стандартов и рекомендаций международных организаций позволил выявить три уровня КЭО: базовый, средний, высокий $[12,13,14]$. На базовом уровне КЭО движущей силой экологических преобразований являются правовые требования и законодательное регулирование в сфере экологии. Для организаций с базовым уровнем характерно выстраивание систем экологического управления, ориентированных на снижение загрязнения окружающей среды с целью выполнения зако- 
нодательных экологических требований. Влияние внешних условий среды, таких как требования рынка, к экологичности продукции и запросы потребителей, приводят к смещению экологических приоритетов компаний в сторону повышения эффективности производства за счет минимизации загрязнения и рационального использовании ресурсов. Это характерно для, так называемого, среднего уровня КЭО, на котором экологическая составляющая является условием конкурентоспособности. Для организаций со средним уровнем КЭО характерно развитие СЭМ, обеспечивающих снижение эмиссий до эффективного уровня, основанной на применении предупредительных мер по охране окружающей среды. Высокий уровень КЭО характеризуется взаимодействием организаций с широким кругом заинтересованных сторон и выстраиванием коммуникаций с партнерами, потребителями, местными сообществами и населением по экологическим вопросам, учет их требований и ожиданий в своих экологических стратегиях и программах развития $[9,15]$. В компаниях с высоким уровнем КЭО экологическая составляющая является частью корпоративного управления, а СЭМ - элементом стратегического развития [10]. Учет экологических приоритетов во всех сферах деятельности организации становится основным принципом СЭМ таких компаний.

Изменение экологических приоритетов, встраивание их в корпоративную систему управления и переход на более высокие уровни КЭО приводят к необходимости совершенствования действующих в организации СЭМ, изменению принципов управления, улучшению бизнес-процессов, расширению функций и взаимодействия с другими системами менеджмента организации. Исследования в области эволюции систем экологического управления и факторов, влияющих на развитие СЭМ, показывают значительное разнообразие подходов к выделению форм развития СЭМ и их содержания [16]. Обычно выделяется три типа СЭМ, которые носят разные названия, но совпадают по общим характеристикам и факторам развития, к главным из которых относят законодательное регулирование, требования рынка, взаимодействие с заинтересованными сторонами и корпоративное измерение экологического развития [17]. Это позволяет говорить о возможности соотнесения описанных выше уровней КЭО с соответствующими им моделями СЭМ.

Первый тип СЭМ характерен для начального этапа развития системы экологического менеджмента, где движущей силой для практических мер по охране окружающей среды выступают законодательные требования, но на корпоративном уровне наблюдается отсутствие приверженности экологическим вопросам $[17,19]$. Ко второму типу относят СЭМ экологизацией производственной сферы с небольшой интеграцией с другими видами деятельности компании [17]. Как правило, здесь речь идет о повышении эффективности за счет рационального использования природных ресурсов, но при этом происходит постепенное внедрение превентивных мер по защите окружающей среды [18], в том числе разработка экологически чистых продуктов, внедрение экологически чистых технологий, систематизация управления окружающей средой [19], а также формирование многофункциональных групп и проведение экологического обучения персонала вспомогательных служб и руководителей [17]. СЭМ третьего типа носят корпоративный характер, предполагающий участие высшего руководства и персонала всей организации [11], 
применяются формы проактивного управления, направленные на развитие и поддержание корпоративной экологической культуры [16].

Несмотря на общность взглядов большинства исследователей, известные классификации не описывают точных характеристик уровней и моделей СЭМ, что не дает возможности определить подходы и инструменты, обеспечивающие переход компании на более высокий уровень КЭО. Для устранения этого методологического пробела нами разработана классификация моделей СЭМ на основе следующих параметров: объект управления, степень интеграции экологической политики в систему управления компании, взаимодействие СЭМ с другими системами управления, персонал, на который ориентированы принимаемые управленческие решения, и его роль в решении экологических задач. В результате было выделено три модели СЭМ: реактивная, превентивная и проактивная модели СЭМ $[8,17,18]$ (табл.1).

Таблица 1

\begin{tabular}{|c|c|c|c|}
\hline \multirow{3}{*}{$\begin{array}{l}\text { Параметр } \\
\text { Объект управления }\end{array}$} & \multicolumn{3}{|c|}{ Модель системы экологического менеджмента } \\
\hline & Реактивная & Превентивная & \multirow{2}{*}{\begin{tabular}{l}
\multicolumn{1}{c}{ Проактивная } \\
Экологические аспекты \\
Социально-экологические аспекты
\end{tabular}} \\
\hline & $\begin{array}{l}\text { Воздействия на окру- } \\
\text { жающую среду }\end{array}$ & $\begin{array}{l}\text { Экологические аспек- } \\
\text { ты }^{1}\end{array}$ & \\
\hline $\begin{array}{l}\text { Степень интегра- } \\
\text { ции экологической } \\
\text { политики в систе- } \\
\text { му управления } \\
\text { компании }\end{array}$ & $\begin{array}{l}\text { Экологическая полити- } \\
\text { ка реализуется в рамках } \\
\text { природоохранных } \\
\text { служб }\end{array}$ & $\begin{array}{l}\text { Экологическая полити- } \\
\text { ка согласована с поли- } \\
\text { тиками других систем } \\
\text { управления }\end{array}$ & $\begin{array}{l}\text { Обязательства и принципы эколо- } \\
\text { гической политики согласованы с } \\
\text { политиками других систем управ- } \\
\text { ления в рамках общих корпоратив- } \\
\text { ных целей и задач }\end{array}$ \\
\hline $\begin{array}{l}\text { Взаимодействие } \\
\text { СЭМ с } \\
\text { системами другими } \\
\text { ления }\end{array}$ & $\begin{array}{l}\text { Функциональная авто- } \\
\text { номия природоохран- } \\
\text { ных служб: взаимодей- } \\
\text { ствие в рамках отдель- } \\
\text { ных функций и задач }\end{array}$ & $\begin{array}{l}\text { Координация: взаимо- } \\
\text { действие с другими } \\
\text { системами управления } \\
\text { в рамках общих бизнес- } \\
\text { процессов СЭМ }\end{array}$ & $\begin{array}{l}\text { Интеграция: приоритетность охра- } \\
\text { ны окружающей среды в бизнес- } \\
\text { процессах других систем управле- } \\
\text { ния, взаимодействие на основе } \\
\text { кросс-функциональных коммуни- } \\
\text { каций и совместного решения } \\
\text { задач и проблем }\end{array}$ \\
\hline Персонал & $\begin{array}{l}\text { Ориентация на персо- } \\
\text { нал природоохранных } \\
\text { служб и и производ- } \\
\text { ственный персонал }\end{array}$ & $\begin{array}{lr}\text { Ориентация на админи- } \\
\text { стративный } \\
\text { (менеджеров) }\end{array}$ & $\begin{array}{l}\text { Ориентация на сотрудников всех } \\
\text { служб и подразделений }\end{array}$ \\
\hline Роль персонала & Не рассматривается & $\begin{array}{l}\text { Объект управления в } \\
\text { рамках системы эколо- } \\
\text { гического менеджмента }\end{array}$ & $\begin{array}{l}\text { Субъект управления, проактивно } \\
\text { содействующий } \\
\begin{array}{l}\text { устойчивости и о ответственности } \\
\text { организации }\end{array}\end{array}$ \\
\hline
\end{tabular}

Источник: составлено автором

Очевидно, что переход от реактивной к превентивной и проактивной моделям СЭМ осуществляется за счет смещения экологической политики в сторону социально-экологических принципов и норм, расширения и углубления взаимодействий СЭМ с другими системами управления, вовлечения персонала всех подразделений компании в деятельность, направленную на поддержание и обеспечение достижения стратегии и целей экологически ответственного ведения бизнеса [17]. И здесь особое значение приобретает консолидация практик УЧР и СЭМ $[3,20]$. Во-первых, реализация проактивного

\footnotetext{
1 Экологический аспект - это элемент деятельности организации, ее продукции или услуг, который взаимодействует или может взаимодействовать с окружающей средой [ГОСТ Р ИСО 14001-2016 «Системы экологического менеджмента. Требования и руководства по применению»]
} 
СЭМ возможна только при участии специалистов всех подразделений и широкого вовлечения персонала в решение экологических задач $[11,21]$, поскольку такие задачи выходят за рамки функционала экологических служб и направлены на решение более широкого круга экологических проблем, в том числе социально-экологических. Во-вторых, такие эффекты как высокая мотивация к экологическим улучшениям и инновациям, заинтересованность в экологическом обучении, снижение экологических рисков, связанных с персоналом, активное участие сотрудников в социально-экологических мероприятиях, внутренний и внешний экологический имидж компании и многие другие, связаны с людьми, а не с наилучшими природоохранными и прочими технологиями [22]. Из вышесказанного следует, что реализация принципов КЭО в компании приводит к развитию экологической направленности УЧР при надлежащей интеграции экологической устойчивости в кадровую политику и консолидации практики УЧР с СЭМ [4, 20, 23].

В результате множества исследований была установлена прямая связь между экологическими показателями организации и практиками УЧР, подчеркивающая необходимость уделять особое внимание отбору, обучению и вознаграждению сотрудников за экологические результаты, повышению вовлеченности персонала, участию высшего руководства в решении экологических вопросов, чтобы формировать экологическое поведение и культуру в компании $[23,24,25,26]$. В ряде работ определена значимая роль подразделений УЧР в обеспечении экологических показателей работы персонала и реализации корпоративной экологической стратегии [27] за счет того, что в исследованных организациях экологическая ответственность присутствовала во всех аспектах деятельности по УЧР и была согласована с ключевыми системами и бизнес-процессами организации. Другими словами, для достижения целей КЭО такие функции, как подбор и найм персонала, обучение, оценка эффективности, вознаграждение, командная работа, вовлечение, расширение прав и возможностей сотрудников могут использоваться в качестве инструментария для реализации экологической стратегии организации и должны соотноситься с задачами экологического менеджмента (табл. 2).

Несмотря на изученность применения практик УЧР в качестве инструментов достижения экологических показателей организации, о динамике взаимосвязи между этими практиками, КЭО и эффективностью экологического менеджмента известно мало $[5,8]$. Мы предположили, что эта взаимосвязь наиболее отчетливо прослеживается при рассмотрении практик УЧР, соответствующих трем моделям СЭМ, описанным выше: реактивной, превентивной, проактивной. Для обоснования этой взаимосвязи дифференциация осуществлялась на организационном уровне исходя из критически значимых при реализации экологических стратегий и политик параметров УЧР, а также применяемых практик УЧР, которые вносят вклад в экологическую результативность (табл. 3).

В реактивной модели СЭМ, соответствующей базовому уровню КЭО, роль УЧР сводится к применению отдельных практик, направленных на устранение и предупреждение несоответствий законодательству в области охраны окружающей среды. В таких моделях экологического менеджмента деятельность кадровых служб ограничивается задачами по обеспечению не- 
обходимого уровня компетенций и информирования персонала об экологических обязанностях и ответственности. Такая модель СЭМ до сих пор существует на предприятиях, поскольку многие компании считают, что чем выше количество экологически подготовленных работников, тем выше способность фирмы адаптироваться к новым правовым экологическим требованиям [35].

Таблииа 2

Практики УЧР, поддерживающие рещение экологических задач организации

\begin{tabular}{|c|c|}
\hline $\begin{array}{c}\text { Практики } \\
\text { учР }\end{array}$ & Основные положения \\
\hline $\begin{array}{l}\text { Проектиро- } \\
\text { вание рабо- } \\
\text { чих мест }\end{array}$ & $\begin{array}{l}\text { Разработка и внедрение новых рабочих мест и должностей с учетом экологических требова- } \\
\text { ний позволяет более эффективно управлять экологическими аспектами организации [29]. } \\
\text { Включение экологических требований в должностные и рабочие инструкции превращает } \\
\text { приверженность вопросам охраны окружающей среды в обязательства сотрудников и спо- } \\
\text { собствует снижению рисков непреднамеренного негативного воздействия на окружающую } \\
\text { среду [11], формирует ответственность за экологические последствия на рабочем месте. }\end{array}$ \\
\hline $\begin{array}{l}\text { Подбор и } \\
\text { найм персо- } \\
\text { нала }\end{array}$ & $\begin{array}{l}\text { Подбор экологически ориентированного персонала оказывает влияние на достижение эколо- } \\
\text { гических показателей и повышает лояльность к экологическим программам и инновациям } \\
\text { организации новых сотрудников }[11] \text {, которые будут более охотно применять свои экологи- } \\
\text { ческие знания в процессе работы, улучшая экологические показатели организации }[3,26] \text {. С } \\
\text { другой стороны, репутация компании как «зеленого» работодателя является эффективным } \\
\text { способом привлечения более компетентных и мотивированных работников }[29,30] \text {. }\end{array}$ \\
\hline $\begin{array}{l}\text { Обучение и } \\
\text { развитие } \\
\text { персонала }\end{array}$ & $\begin{array}{l}\text { Экологическое обучение предоставляет сотрудникам необходимые знания об экологической } \\
\text { политике и экологических аспектах организации, природоохранных решениях и мероприя- } \\
\text { тиях, повышает осведомленность работников о воздействии их деятельности на окружаю- } \\
\text { щую среду [31], интеллектуально и эмоционально вовлекает сотрудников в экологические } \\
\text { проблемы и информирует их о возможных решениях текущих экологических задач }[11,26] \text {, } \\
\text { повышает скорость и уровень принятия экологических нововведений, противодействует } \\
\text { сопротивлению изменениям [32]. }\end{array}$ \\
\hline \begin{tabular}{l|} 
Оценка \\
эффектив- \\
ности со- \\
трудников \\
\end{tabular} & $\begin{array}{l}\text { Оценка дает сотрудникам ценную и конструктивную обратную связь об их вкладе в эколо- } \\
\text { гическую результативность [22], обеспечивает предотвращение нежелательных экологиче- } \\
\text { ских последствий в работе и формирует экологически-ответственное поведение персонала } \\
{[8,25] \text {. }}\end{array}$ \\
\hline $\begin{array}{l}\text { Стимулиро- } \\
\text { вание и } \\
\text { поддержка } \\
\text { персонала }\end{array}$ & $\begin{array}{l}\text { Стимулирование и поддержка персонала обеспечивают привлечение, удержание и мотива- } \\
\text { цию сотрудников для достижения экологических целей и экологических показателей }[11 \text {, } \\
22] \text {, повышает уровень заинтересованности и вовлеченности в экологические вопросы и } \\
\text { формирует экологическое поведение }[3,33,34] \text {. }\end{array}$ \\
\hline
\end{tabular}

Источник: составлено автором

С возрастанием значения экологической составляющей в корпоративных стратегиях и переходе на более высокие уровни КЭО усиливается роль и расширяется участие персонала в реализации экологических, экологоэкономических и социально-экологических целей компании. В связи, с чем переход на превентивные и проактивные модели СЭМ определяет необходимость изменения методов и подходов к управлению персоналом в сторону эколого-ориентированных и эколого-интегрированных политик и практик $[7,8$, 20]. На среднем и высоком уровне КЭО требуются новые компетенции, в том числе у руководителей и специалистов вспомогательных служб, поэтому «зеленый найм» и поиск «зеленых талантов» становятся мерой проактивного влияния на экологическую результативность компании. Это также приводит к изменениям в процедурах подготовки и обучения персонала, требует расширенных программ информирования с использованием разных форм и каналов коммуникаций, активной поддержки экологических инициатив сотрудников. Для высокого уровня КЭО характерны эколого-интегрированные практики 
УЧР [20], направленные на повышение уровня вовлеченности и формирования экологического поведения сотрудников, что требует внедрения корпоративных программ экологического развития персонала, согласованных с задачами СЭМ и поддерживающими экологические ценности компании.

Таблица 3

Параметры деятельности по УЧР в моделях СЭМ

\begin{tabular}{|c|c|c|c|}
\hline \multirow{2}{*}{$\begin{array}{c}\text { Параметры } \\
\text { деятельности } \\
\text { по УЧР } \\
\end{array}$} & \multicolumn{3}{|c|}{ Модель системы экологического менеджмента } \\
\hline & Реактивная & Превентивная & Проактивная \\
\hline Политика УЧР & $\begin{array}{l}\text { Не ориентирована на эко- } \\
\text { логические вопросы }\end{array}$ & \begin{tabular}{|l|} 
Эколого-ориентированная: \\
учитывает экологическую \\
политику организации
\end{tabular} & $\begin{array}{l}\text { Эколого-интегрированная: } \\
\text { «зеленые» принципы и функ- } \\
\text { ции (GHRM) }\end{array}$ \\
\hline \multirow{4}{*}{ Персонал } & \multicolumn{3}{|c|}{ Персонал природоохранных служб } \\
\hline & \multicolumn{3}{|c|}{ Персонал производственных подразделений } \\
\hline & & \multicolumn{2}{|c|}{ Административный аппарат (менеджеры) } \\
\hline & & & $\begin{array}{l}\text { Сотрудники всех подразделе- } \\
\text { ний и уровней }\end{array}$ \\
\hline $\begin{array}{l}\text { Взаимодей- } \\
\text { ствие с приро- } \\
\text { доохранными } \\
\text { службами }\end{array}$ & $\begin{array}{l}\text { Задачи, связанные с персо- } \\
\text { налом, решаются автоном- } \\
\text { но. Взаимодействия в } \\
\text { рамках отдельных функци- } \\
\text { ональных задач }\end{array}$ & $\begin{array}{l}\text { Взаимодействие расширен- } \\
\text { ному кругу вопросов, каса- } \\
\text { ющихся подбора, обучения } \\
\text { и оценки персонала в рам- } \\
\text { ках общих бизнес-процессов } \\
\text { СЭМ }\end{array}$ & $\begin{array}{l}\text { Взаимодействия по широкому } \\
\text { кругу вопросов корпоративной } \\
\text { экологической стратегии на } \\
\text { основе кросс-функциональных } \\
\text { коммуникаций и совместного } \\
\text { решения задач и проблем }\end{array}$ \\
\hline $\begin{array}{l}\text { Взаимодей- } \\
\text { ствие между } \\
\text { УЧР и СЭМ }\end{array}$ & $\begin{array}{l}\text { Автономия: деятельность } \\
\text { по учР дистанцирована от } \\
\text { экологических задач орга- } \\
\text { низации, разовые меропри- } \\
\text { ятия с участием персонала, } \\
\text { ориентированные на реше- } \\
\text { ние отдельных уже воз- } \\
\text { никших экологических } \\
\text { проблем }\end{array}$ & $\begin{array}{l}\text { Координация: } \text { практики } \\
\text { уЧР учитывают экологиче- } \\
\text { скую политику компании, } \\
\text { систематические экологиче- } \\
\text { ские мероприятия с участи- } \\
\text { ем персонала }\end{array}$ & $\begin{array}{l}\text { Интеграция: политики и прак- } \\
\text { тики УЧР основаны на «зеле- } \\
\text { ных» принципах и проактивно } \\
\text { содействуют реализации кор- } \\
\text { поративной } \\
\text { стратегии }\end{array}$ \\
\hline $\begin{array}{l}\text { Целевая функ- } \\
\text { ция УЧР }\end{array}$ & Отсутствует & $\begin{array}{l}\text { Подготовка, контроль и } \\
\text { стимулирование экологиче- } \\
\text { ской результативности } \\
\text { сотрудников }\end{array}$ & $\begin{array}{l}\text { Применение всеобъемлющие } \\
\text { системы HR-политик и прак- } \\
\text { тик, основанных на экологиче- } \\
\text { ских ценностях компании }\end{array}$ \\
\hline \multicolumn{4}{|c|}{ Практики УЧР } \\
\hline $\begin{array}{l}\text { Организаци- } \\
\text { онное проек- } \\
\text { тирование }\end{array}$ & $\begin{array}{l}\text { Рабочие места проектиру- } \\
\text { ются в соответствии с } \\
\text { экологическими требовани- } \\
\text { ями и нормативами } \\
\end{array}$ & \multicolumn{2}{|c|}{$\begin{array}{l}\text { Проектирование «зеленых» } \\
\text { и требований к персоналу }\end{array}$} \\
\hline $\begin{array}{l}\text { Подбор персо- } \\
\text { нала }\end{array}$ & $\begin{array}{l}\text { Подбор и найм сотрудни- } \\
\text { ков по требованиям эколо- } \\
\text { гической безопасности }\end{array}$ & $\begin{array}{l}\text { Поиск, оценка и отбор } \\
\text { специалистов с экологиче- } \\
\text { скими компетенциями }\end{array}$ & $\begin{array}{l}\text { Поиск, привлечение и найм } \\
\text { «зеленых талантов» }\end{array}$ \\
\hline $\begin{array}{l}\text { Введение в } \\
\text { организацию }\end{array}$ & $\begin{array}{l}\text { Вводное } \quad \text { экологическое } \\
\text { обучение и инструктаж }\end{array}$ & $\begin{array}{l}\text { Вводное обучение новых } \\
\text { сотрудников по вопросам } \\
\text { экологической стратегии и } \\
\text { политики организации }\end{array}$ & $\begin{array}{l}\text { Интеграционные } \text { экологиче- } \\
\text { ские мероприятия для новых } \\
\text { сотрудников }\end{array}$ \\
\hline \multirow{3}{*}{$\begin{array}{l}\text { Оценка эколо- } \\
\text { гической эф- } \\
\text { фективности } \\
\text { персонала }\end{array}$} & \multicolumn{3}{|c|}{$\begin{array}{l}\text { Оценка и контроль выполнения персоналом экологических требований природоохранных } \\
\text { служб и производственных подразделений }\end{array}$} \\
\hline & & $\begin{array}{l}\text { Оценка } \quad \text { экологических } \\
\text { результатов } \\
\text { дибобеты руково- }\end{array}$ & $\begin{array}{l}\text { Оценка деятельности руково- } \\
\text { дителей по вовлечению персо- } \\
\text { нала в экологические инициа- } \\
\text { тивы и проекты } \\
\end{array}$ \\
\hline & & $\begin{array}{l}\text { Оценка и контроль выпол- } \\
\text { нения экологических требо- } \\
\text { ваний персоналом непроиз- } \\
\text { водственных и вспомога- } \\
\text { тельных подразделений }\end{array}$ & $\begin{array}{l}\text { Оценка экологических компе- } \\
\text { тенций сотрудников, монито- } \\
\text { ринг эко-вовлеченности персо- } \\
\text { нала }\end{array}$ \\
\hline
\end{tabular}


Окончание таблицы 3

\begin{tabular}{|c|c|c|c|}
\hline \multirow{2}{*}{$\begin{array}{l}\text { Параметры } \\
\text { деятельности } \\
\text { по УЧР } \\
\end{array}$} & \multicolumn{3}{|c|}{ Модель системы экологического менеджмента } \\
\hline & Реактивная & Превентивная & Проактивная \\
\hline \multirow{5}{*}{$\begin{array}{l}\text { Обучение } \\
\text { развитие пер- } \\
\text { сонала }\end{array}$} & \multicolumn{3}{|c|}{ Обязательное обучение, подготовка и информирование персонала } \\
\hline & & \multicolumn{2}{|c|}{ Развивающее экологическое обучение } \\
\hline & & \multicolumn{2}{|c|}{$\begin{array}{l}\text { Внедрение командной работы над экологическими проектами } \\
\text { и инициативами }\end{array}$} \\
\hline & & \multicolumn{2}{|c|}{$\begin{array}{l}\text { Систематический сбор предложений от сотрудников, направ- } \\
\text { ленных на улучшение природоохранных показателей }\end{array}$} \\
\hline & & $\begin{array}{l}\text { Формирование } \\
\text { ской культуры }\end{array}$ & $\begin{array}{l}\text { Формирование «зеленых» } \\
\text { моделей поведения персонала } \\
\text { через развитие экологических } \\
\text { компетенций; выявление «зе- } \\
\text { леных» лидеров; формирова- } \\
\text { ние «зеленых» команд }\end{array}$ \\
\hline \multirow[b]{4}{*}{$\begin{array}{l}\text { Стимулирова- } \\
\text { ние персонала }\end{array}$} & \multicolumn{3}{|c|}{ Материальные поощрения за выполнение нормативных природоохранных показателей } \\
\hline & & \multirow{2}{*}{\multicolumn{2}{|c|}{$\begin{array}{l}\text { Материальные поощрения за выполнение плановых показа- } \\
\text { телей экологической результативности }\end{array}$}} \\
\hline & & & \\
\hline & & $\begin{array}{l}\text { Стимулирование экологиче- } \\
\text { ских инициатив и социаль- } \\
\text { но-экологической деятель- } \\
\text { ности сотрудников }\end{array}$ & 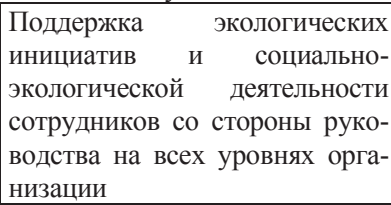 \\
\hline
\end{tabular}

Источник: составлено автором

Перечисленные эффекты не выражаются в прямых экологоэкономических показателях, но дают более высокий долгосрочный результат, направленный на укрепление экологического поведения и экологической культуры, что в свою очередь является одним из условий экологического ответственного и устойчивого развития компании. Таким образом, консолидация практик и инструментов СЭМ и УЧР, взаимно усиливающих внутренние возможности компании, вносит существенный вклад в развитие КЭО.

\section{Заключение}

Сегодня многие исследователи считают, что в реализации корпоративной экологической стратегии компании ключевая роль должна отводиться УЧР, потому что принимаемые экологические меры будут эффективными только тогда, когда все сотрудники организации являются непосредственными и активными участниками экологических улучшений, что обеспечивается применением совместно с практиками экологического менеджмента экологоориентированных и эколого-интегрированных практик УЧР [20].

Результаты исследования доказывают, что УЧР необходимо рассматривать, с одной стороны, как фактор успешности и эффективности СЭМ, а с другой, как механизм ведения экологически ответственного бизнеса, основанный на совместном использовании инструментов и практик УЧР и СЭМ. Выводы и модели могут быть полезны для дальнейших теоретических и эмпирических исследований, а также для диагностики и оценки степени соответствия HRсистем экологическим целям компании. Перспективными научными направлениями в обозначенной области являются вопросы развития СЭМ от реактивной к превентивной и проактивной моделям на основе организационных механиз- 
мов консолидации систем УЧР и СЭМ, а также оценка влияния этих процессов на реализацию корпоративных экологических стратегий.

\section{Список источников / References}

1. Rajala R., Westerlund M., Lampikoski T. Environmental sustainability in industrial manufacturing: re-examining the greening of Interface's business model. Journal of Cleaner Production, 2016, vol. 1151, pp. 52-61. DOI: 10.1016/j.jclepro.2015.12.057

2. Long Ch., Lin J. The Impact of Corporate Environmental Responsibility Strategy on Brand Sustainability: an Empirical Study Based on Chinese Listed Companies. Nankai Business Review International, 2018, vol. 9, no.3, pp. 366-394. DOI: 10.1108/NBRI-082017-0044

3. Wehrmeyer W.Greening People: Human Resource and Environmental Management. New York: Greenleaf. 1st Edition, 1996, 416 p. DOI: 10.4324/9781351283045

4. Cheema S., Javed F. The effects of corporate social responsibility toward green human resource management: The mediating role of sustainable environment. Cogent Business \& Management, 2017, vol. 4, no.1, DOI: 10.1080/23311975.2017.1310012

5. Jackson S.E., Renwick D.W.S., Jabbour C.J.C., Muller-Camen M.State-of-the-Art and future directions for Green Human Resource Management: introduction to the special issue. German Journal of Research in Human Resource Management, 2011, vol. 25, no. 2, pp. 99-116, DOI: $10.2307 / 23279428$

6. Aykan E. Gaining a Competitive Advantage through Green Human Resource Management. In book: Corporate Governance and Strategic Decision Making, 2017, pp. 159177. DOI:10.5772/intechopen. 69703

7. Masri H., Jaaron A. Assessing green human resources management practices in Palestinian manufacturing context: An empirical study. Journal of Cleaner Production, 2017, vol. 143, pp. 474-489. DOI: 10.1016/j.jclepro.2016.12.087

8. Jabbour C.J.C., Santos F.C.A., Nagano M.S. Contributions of HRM throughout the stages of environmental management: methodological triangulation applied to companies in Brazil. The International Journal of Human Resource Management, 2010, vol. 21, no.7, pp. 1049-1089. DOI: 10.1080/09585191003783512

9. Bansal P., Roth K. Why companies go green: a model of ecological responsiveness. Academy of Management Journal, 2000, vol. 43, no.4, pp. 717-736. DOI: $10.2307 / 1556363$

10. Williamson D., Lynch-Wood G., Ramsay J. Drivers of environmental behavior in manufacturing SMEs and the implications for CSR. Journal of Business Ethics, 2006, vol. 67, no 3, pp. 317-330, DOI: 10.1007/s10551-006-9187-1

11. Разумовская И.В. Экологическая ответственность предприятий газовой отрасли и инструменты ее обеспечения// Вестник ЮРГТУ (НПИ). 2016. № 6. С.30-35. [Razumovskaya I.V. Ekologicheskaya otvetstvennost' predpriyatiy gazovoy otrasli i instrumenty yeye obespecheniya [Environmental responsibility of enterprises of the gas industry and tools for its support] // Vestnik YURGTU (NPI) = Bulletin of SRSTU (NPI). 2016. No. 6. P.30-35.]

12. Благов Ю.Е. Концепция корпоративной социальной ответственности и стратегическое управление // Российский журнал менеджмента,2004, №3, с. 1734.[Blagov YU.Ye. Kontseptsiya korporativnoy sotsial'noy otvetstvennosti i strategicheskoye upravleniye [The concept of corporate social responsibility and strategic management // Rossiyskiy zhurnal menedzhmenta $=$ Russian Journal of Management №3, 2004. s. 17-34.]

13. Полякова А.Г. Правовой анализ институционального механизма корпоративной социальной ответственности российских промышленных корпораций// BaikalResearchJournal, 2016. T. 7, № 1. c. 11. DOI 10.17150/2411-6262.2016.7(1).11 [Polya- 
kova A.G. Pravovoy analiz institutsional'nogo mekhanizma korporativnoy sotsial'noy otvetstvennosti rossiyskikh promyshlennykh korporatsiy [Legal analysis of the institutional mechanism of corporate social responsibility of Russian industrial corporations] // Baikal Research Journal, 2016. T. 7, № 1. c. 11. DOI 10.17150/24116262.2016.7(1).11]

14. Костин А.Е. Корпоративная ответственность и устойчивое развитие. М.: Институт устойчивого развития Общественной палаты Российской Федерации. Центр экологической политики России, 2013. 80 с. [Kostin A.Ye. Korporativnaya otvetstvennost' $i$ ustoychivoye razvitiye [Corporate Responsibility and Sustainability.] M.: Institut ustoychivogo razvitiya Obshchestvennoy palaty Rossiyskoy Federatsii. Tsentr ekologicheskoy politiki Rossii, 2013. $80 \mathrm{~s}$.

15. Dummett K. Drivers for Corporate Environmental Responsibility (CER). Environment, Development and Sustainability, 2006, vol. 8, no.3, pp. 375-389. DOI: 10.1007/s10668005-7900

16. Kolk A., Mauser A. The evolution of environmental management: from stage models to performance evaluation. Business Strategy and the Environment, 2002, vol.11, pp. 1431. DOI: $10.1002 /$ bse. 31

17. Potrich L., Cortimiglia M.N., Medeiros J.F.A systematic literature review on firm-level proactive environmental management. Journal of Environmental Management, 2019, vol. 243, pp. 273-286, DOI:10.1016/j.jenvman.2019.04.110

18. Ormazabal M., Sarriegi J.M. Environmental Management Evolution: Empirical Evidence from Spain and Italy. Business Strategy and the Environment, 2012, vol. 23, no.2, pp. 73-88. DOI: 10.1002/bse.1761

19. Berry M.A., Rondinelli D.A. Proactive corporate environmental management: A new industrial revolution. Academy of Management Perspectives, 1998, vol. 12, no.2, pp. 38-50. DOI: 10.5465/ame.1998.6505

20. Арзамасова Г.С., Эсаулова И.А. Green Human Resource Management - концепция управления человеческими ресурсами экологически ответственного бизнеса // Вестник НГУЭУ. 2020, № 2. C. 42-52. DOI: 10.34020/2073-6495-2020-2-042-053 [Arzamasova G.S., Esaulova I.A. Green Human Resource Management - kontseptsiya upravleniya chelovecheskimi resursami ekologicheski otvetstven-nogo biznesa [Green Human Resource Management - the concept of human resource management of an environmentally responsible business]// Vestnik $N G U E U=$ Bulletin of NSUU, 2020, № 2. S. 42-52. DOI: 10.34020/2073-6495-2020-2-042-053]

21. Mishra P. Green human resource management: A framework for sustainable organizational development in an emerging economy. International Journal of Organizational Analysis, 2017, vol. 25, no.5, pp. 762-788. DOI: 10.1108/IJOA-11-2016-1079

22. Labella-Fernández A., Martínez-del-Río J. Green Human Resource Management. In book: W. Leal Filho et al. (eds.). Responsible Consumption and Production, Encyclopedia of the UN Sustainable Development Goals, 2019, pp. 1-12. DOI: 10.1007/978-3319-71062-4 113-1.

23. Saeed B.B., Âfsar B., Hafeez S., Khan I., Tahir M., Afridi M.A. Promoting employee's proenvironmental behavior through green human resource management practices. Corporate Social Responsibility and Environmental Management, 2018, vol. 26, no.1, pp.424-438. DOI: $10.1002 /$ csr.1694

24. Del Brío J.Á., Fernández E., Junquera B. Management and employee involvement in achieving an environmental action-based competitive advantage: an empirical study. The International Journal of Human Resource Management, 2007, vol.18, no 4, pp. 491-522. DOI: 10.1080/09585190601178687

25. Gholami H., Rezaei G., Saman M.Z.M., Sharif S., Zakuan N. State-of-the-art green HRM system: sustainability in the sports center in Malaysia using a multi-methods ap- 
proach and opportunities for future research. Journal of Cleaner Production, 2016, vol. 124, pp. 142-163. DOI: 10.1016/j.jclepro.2016.02.105

26. Renwick D.W., Redman, T., Maguire S. Green Human Resource Management: A Review and Research Agenda. International Journal of Management Reviews, 2013, vol. 15, no.1, pp. 1-14. DOI: 10.1111/j.1468-2370.2011.00328

27. Sheikh W., Islam M.S, Rahman F. Implementing Green Human Resource Management: Cost-Effective Strategies and Tools. Journal Entrepreneurship \& Organization Management, 2015, vol.8, no.1, p. 264. DOI: 10.4172/2169-026X.1000264

28. Wagner M. Environmental Management Activities and Sustainable HRM in German Manufacturing Firms - Incidence, Determinants, and Outcomes. German Journal of Research in Human Resource Management, 2011, vol. 25, no. 2, Pp. 157-177. DOI: $10.2307 / 23279431$

29. Opatha H.H.D.N.P., Arulrajah A. (2014). Green Human Resource Management: A Simplified General Reflections. International Business Research, 2014, vol. 8, pp. 101 112, DOI: $10.5539 /$ ibr.v7n8p101

30. Dögl C., Holtbrügge D. Corporate environmental responsibility, employer reputation and employee commitment: an empirical study in developed and emerging economies. The International Journal of Human Resource Management, 2014, vol. 25, no.12. Pp. 1739-1762. DOI: 10.1080/09585192.2013.859164.

31. Ji L., Huang J., Liu Z., Zhu H., Cai Z.The effects of employee training on the relationship between environmental attitude and firms' performance in sustainable development. The International Journal of Human Resource Management, 2011, vol. 23, no.14, pp. 2995-3008. DOI:10.1080/09585192.2011.637072

32. Ramus C.A. Organizational Support for Employees: Encouraging Creative Ideas for Environmental Sustainability. California Management Review, 2001, vol. 43, no.3, pp. 85-105. DOI: $10.2307 / 41166090$

33. Paille' P., Chen Y., Boiral O., Jin J. The Impact of Human Resource Management on Environmental Performance: An Employee-Level Study. Journal of Business Ethics, 2014, vol. 121, pp. 451-466. DOI: 10.1007/s10551-013-1732-0.

34. Kim Y.J., Kim W.G., Choi H.M., Phetvaroon K. The effect of green human resource management on hotel employees' eco-friendly behavior and environmental performance. International Journal of Hospitality Management, 2019, vol. 76, pp. 83-93. DOI: $10.1016 /$ j.ijhm.2018.04.007.

35. Vidal-Salazar M.D., Cordón-Pozo E., Ferrón-Vilchez V. Human resource management and developing proactive environmental strategies: The influence of environmental training and organizational learning. Human Resource Management, 2012, vol.51, no.6, pp. 905-934. DOI:10.1002/hrm.21507

\section{Сведения об авторе / About author}

Арзамасова Галина Сергеевна, старший преподаватель кафедры «Охрана окружающей среды», соискатель кафедры «Менеджмент и маркетинг», Пермский национальный исследовательский политехнический университет. 614990 Россия, г. Пермь, Комсомольский проспект, 29. ORCID ID 0000-0001-7829-6970.E-mail: Arzamasova_g@mail.ru

Galina S. Arzamasova, Senior Lecturer of the Environmental Protection Department, PhD student of Management and Marketing Department, Perm National Research Polytechnic University. 29 Komsomolsky Prospekt, Perm, Russia 614990. ORCID ID 0000-0001-7829-6970.E-mail: Arzamasova_g@mail.ru 